\title{
Análise exploratória dos dados gerados pela perícia oficial do estado do Rio de
}

\section{Janeiro: Aplicações e desafios}

\author{
Exploratory analysis of data generated by the official forensic investigation units of the state of Rio \\ de Janeiro: Applications and challenges \\ Análisis exploratorio de datos generados por el peritaje oficial del estado de Río de Janeiro: \\ Aplicaciones y desafíos
}

Recebido: 16/07/2021 | Revisado: 22/07/2021 | Aceito: 23/07/2021 | Publicado: 01/08/2021

\author{
Alexandre Giovanelli \\ ORCID: https://orcid.org/0000-0002-7452-323X \\ Instituto de Pesquisa e Perícia em Genética Forense, Brasil \\ E-mail: agiovanelli@gmail.com
}

\begin{abstract}
Resumo
O desenvolvimento de sistemas de informação consistentes sobre a produção de exames e laudos é fundamental para o diagnóstico e o planejamento estratégico da perícia oficial. O objetivo do trabalho foi delinear algumas estratégias metodológicas para o uso dos dados produzidos pela polícia técnica. Através de um recorte temporal, buscou-se, por um lado, evidenciar os principais gargalos que dificultam a consolidação de dados. Por outro lado, pretendeu-se apontar caminhos para a construção de indicadores que permitam a alocação adequada de recursos humanos e materiais e a análise integrada da investigação policial com o trabalho da perícia oficial. Foram analisados a série temporal de solicitações de exames periciais, bem como os tipos de perícia efetuados pelos postos de perícia criminal e perícia médico legal do estado do Rio de Janeiro no período de julho de 2013 a julho de 2016. Esses dados foram confrontados, ainda, com as estatísticas oficiais de criminalidade do estado. Os resultados indicam a necessidade de ajuste da organização espacial das unidades de perícia em consonância com a organização estabelecida para as demais unidades de segurança pública do Rio de Janeiro. Além disso, foram observadas dinâmicas espaciais e temporais bastante diferenciadas para os postos de perícia e entre serviço médico legal e serviço de perícia criminal. Também foi observada a necessidade de uso dos dados de criminalidade gerado pelas delegacias para a compreensão da demanda dos postos de perícia.
\end{abstract}

Palavras-chave: Perícia criminal; Perícia médico-legal; Polícia técnico-científica; Métricas policiais; Investigação policial.

\begin{abstract}
The development of consistent information on the production of forensic exams is essential for the diagnosis and strategic planning of official forensic investigation units. The objective of this work was to outline some methodological strategies for the use of data produced by the forensic investigation units. Through a time series we sought to highlight the bottlenecks that hinder data consolidation. On the other hand, it was intended to point out ways for the construction of indicators that allow the adequate allocation of human and material resources and the integrated analysis of the police investigation with the work of the forensic scientists. The time series of requests for expert examinations were analyzed, as well as the types of exams carried out by the criminal and medical forensic units of the state of Rio de Janeiro from July 2013 to July 2016. These data were compared with official state criminal data. The results indicate the need to adjust the spatial organization of the forensic investigation units in line with the organization established for the other public security units in Rio de Janeiro. In addition, very different spatial and temporal dynamics were observed for the forensic investigations units and between the forensic medical unit and the criminal expertise unit. It was also noted the need to use crime data generated by the police stations to understand the demand for forensic investigations units.
\end{abstract}

Keywords: Criminal forensics; Medical legal expertise; Forensic police; Police metrics; Police investigation.

\section{Resumen}

El desarrollo de sistemas de información coherentes sobre la producción de exámenes e informes es fundamental para el diagnóstico y la planificación estratégica de la pericia oficial. El objetivo del trabajo fue esbozar algunas estrategias metodológicas para el uso de datos producidos por la policía técnica. A través de un marco de tiempo, buscamos resaltar las principales limitaciones que dificultan la consolidación de datos. Por otro lado, se pretendió señalar caminos para la construcción de indicadores que permitan la adecuada asignación de recursos humanos y materiales y 
el análisis integrado de la investigación policial con el trabajo de la pericia oficial. Se analizó la serie temporal de solicitudes de peritajes, así como los tipos de exámenes realizados por las unidades de medicina forense y criminalística del estado de Río de Janeiro en el período de julio de 2013 a julio de 2016. También se compararon estos datos, con estadísticas oficiales de delincuencia del estado. Los resultados indican la necesidad de adecuar la organización espacial de las unidades de pericia oficiales a la organización establecida para las demás unidades de seguridad pública en Río de Janeiro. Además, se observaron dinámicas espaciales y temporales muy diferentes para los puestos periciales y entre el servicio médico forense y el servicio de criminalística. También se señaló la necesidad de utilizar los datos delictivos generados por las comisarías para comprender la demanda de puestos de expertos.

Palabras clave: Perícia criminalística; Perícia médica forense, Policía técnica científica; Métricas policiales; Investigación policial.

\section{Introdução}

A polícia técnico-científica é uma função de estado, legalmente prevista no sistema judiciário e que tem como atribuição os exames de corpo de delito, a qual abrange a avaliação de materiais, o exame de pessoas e cadáveres e a observação e análise de vestígios encontrados em local de crime (Brasil, 1941).

O trabalho das instituições periciais é fundamental para o esclarecimento dos eventos criminais e, por conseguinte, para o aumento das taxas de elucidação de crimes, indiciando autores suspeitos e permitindo aos promotores de justiça identificar os réus nos processos penais (Medeiros, 2020). Segundo Zaverucha (2003, p.102), a atuação da perícia criminal e médico-legal é essencial para o embasamento da decisão judicial e sua livre atuação tem sido evocada como imprescindível para a defesa dos direitos e garantias fundamentais das pessoas. Esse mesmo autor chama a atenção para o fato de que o funcionamento inadequado dos órgãos periciais contribui para o aumento da violência e da impunidade.

Por sua vez, o índice de esclarecimento de crimes violentos no Brasil é muito baixo. Estudos diversos (Cano \& Duarte, 2010; Miranda et al., 2010, Misse, 2010; Ribeiro \& Lima, 2020) têm demonstrado que grande parte dos bloqueios resulta da baixa qualidade do trabalho de investigação policial bem como da pequena utilização de laudos periciais. No Estado do Rio de Janeiro, mais de $90 \%$ dos indiciamentos de suspeitos de homicídios resulta da oportunidade de flagrantes e não do resultado de investigações policiais. Além disso, os laudos periciais, seja pela insuficiência de informações técnicas, seja pela demora na produção, trazem pouca contribuição para a investigação policial (Misse, 2010).

De fato os órgãos periciais estão imersos, por razões históricas e administrativas, na cultura policial, de tal maneira que os métodos de investigação científica acabam por ser minimizados em relação aos métodos adotados pelas polícias judiciárias estaduais, qual seja, a investigação de natureza inquisitorial, em que a eleição de um culpado é precedida dos indícios materiais (Giovanelli \&Garrido, 2011). Assim, os baixos investimentos em infraestrutura e capacitação, a existência de uma cultura policial de desvalorização da perícia e a própria adoção de métodos não científicos por parte dos profissionais da perícia tem tornado o laudo pericial um instrumento muito pouco efetivo para a instrumentalização dos processos criminais (Medeiros, 2016; Rangel, 2017; Medeiros, 2020; Platero \& Vargas, 2017).

A reestruturação da polícia técnico-científica é condição necessária para o fortalecimento da produção da prova material e consequentemente da investigação de crimes. Entre as medidas a serem tomadas para a modernização dos órgãos de perícia oficial, pode-se mencionar a capacitação de seus agentes e a melhoria dos recursos técnicos disponíveis. Não menos relevante, o desenvolvimento de sistemas de informação e controle da produção de exames e laudos da perícia oficial é um passo fundamental para a elaboração de diagnóstico que subsidiem o planejamento estratégico e a gestão do sistema de polícia técnica (Giovanelli \& Souza, 2005; Kahn, 2014). Além disso, a informação gerada pela perícia oficial pode trazer importantes benefícios para a sociedade. Quanto maior a diversidade das fontes geradoras de informação, maior é o controle sobre o processo de geração, disseminação e qualidade desses dados. Ou seja, a transparência dos dados é garantida, contribuindo para a democratização da informação.

O objetivo do trabalho foi delinear algumas estratégias metodológicas para o uso dos dados produzidos pela polícia 
técnica. Através de um recorte temporal, buscou-se, por um lado, evidenciar os principais gargalos que dificultam a consolidação de dados. Por outro lado, pretendeu-se apontar caminhos para a construção de indicadores que permitam a alocação adequada de recursos humanos e materiais e a análise integrada da investigação policial com o trabalho da perícia oficial.

\section{Metodologia}

Trata-se de estudo quantitativo, de caráter descritivo, com foco na demanda de exames periciais do estado do Rio de Janeiro. As pesquisas descritivas têm como objetivo primordial a descrição das características de determinada população ou fenômeno ou, então, o estabelecimento de relações entre variáveis (Gil, 2017). No método quantitativo, os dados quantitativos ou numéricos são coletados por meio do uso de medições de grandezas e analisados através de porcentagens, estatísticas, métodos numéricos e analíticos e/ou fórmulas matemáticas aplicáveis a algum processo (Pereira et al., 2018).

As informações sobre população e área territorial da cidade do Rio de Janeiro foram obtidos a partir da base "Data.Rio", disponibilizadas pela Prefeitura do Rio de Janeiro, no site: https://www.data.rio. Para os demais municípios do estado do Rio de Janeiro utilizou-se como base o censo de 2010, disponibilizados no site do IBGE (https://www.ibge.gov.br) e do IPEA (disponível em http://www.ipeadata.gov.br). Os dados de registros de ocorrência foram obtidos a partir do site do Instituto de Segurança Pública - ISP (disponível em https://www.isp.rj.gov.br) para o período de julho de 2013 a julho de 2016. Os seguintes valores dos indicadores de criminalidade disponibilizados no site foram somados, de maneira a formar as seguintes categorias de dados agregados: 1) homicídios: somatório de homicídio doloso, lesão corporal seguida de morte, latrocínio, homicídio decorrente de intervenção policial - auto de resistência, policiais militares mortos em serviço, policiais civis mortos em serviço; 2) lesões corporais: somatório de tentativa de homicídio, lesão corporal dolosa, estupro; 3) crimes de trânsito: somatório de homicídio culposo, lesão corporal culposa; 4) crimes contra o patrimônio: somatório de roubo a estabelecimento comercial, roubo a residência, roubo de veículo, roubo de carga, roubo a transeunte, roubo em coletivo, roubo a banco, roubo de caixa eletrônico, roubo de aparelho celular, roubo com condução da vítima para saque em instituição financeira (IF), furto de veículos, extorsão mediante sequestro, extorsão, extorsão com momentânea privação da liberdade (sequestro relâmpago), estelionato. Para os demais indicadores de criminalidade foram mantidos os valores originais apresentados pelo ISP, sendo eles: 5) drogas apreendidas; 6) armas apreendidas; 7) total de registros de ocorrência.

Os dados do ISP são apresentados por AISP (com detalhamento das delegacias que compõem cada área integrada) e por RISP. Por sua vez, cada unidade de perícia (Posto Regional de Polícia Técnico-Científica) apresenta uma área de abrangência que compreende uma ou mais delegacias que por sua vez podem ou não coincidir com as AISPs definidas pela Secretaria de Segurança Pública (SESEG). Sendo assim, os indicadores de criminalidade foram ajustados (somados) de maneira a agregar as delegacias abrangidas para cada unidade pericial. O objetivo desta disposição dos dados foi testar a hipótese inicial de que a quantidade de registros de ocorrência registrados nas delegacias da circunscrição atendida pelas unidades de perícia teria correspondência com a demanda de exames solicitados.

As informações sobre o número de peritos por unidade de perícia e a demanda de exames periciais foram fornecidos pelo Departamento Geral de Polícia Técnico-Científica (DGPTC) da Polícia Civil do Rio de Janeiro. Na ocasião foram fornecidos dois tipos de planilhas de dados: a) uma contendo informações consolidadas do número total de exames solicitados para o período de julho de 2013 a julho de 2016, sem detalhamento por tipo de exame e b) uma planilha detalhada contendo os tipos de exames por posto de perícia, apenas para o ano de 2015. Os exames solicitados incluíram as perícias em locais de crime e em objetos no caso da perícia criminal e os exames em vivos e as necrópsias para o caso da perícia médico-legal. Esses valores foram considerados como a demanda por exames periciais. Nas análises de correlação, para se manter a homogeneidade dos dados, foram considerados apenas os meses em que havia informações disponíveis tanto para a perícia 
criminal quanto para a perícia médico-legal. Neste caso, do período acima citado, foram excluídas as datas de julho e agosto de 2013, junho de 2014, março, maio, junho e julho de 2016, pois nestes meses não foram fornecidos os índices da perícia criminal e/ou da perícia médico-legal.

Para o ano de 2015, foram obtidos dados detalhados dos tipos de exames solicitados às unidades de perícia médicolegal, os quais foram agregados, para análise, da seguinte maneira: a) Exames de necrópsias: incluindo as categorias "Exame de Necrópsia", "Exame de Local de Exumação", "Exame em Ossada"; b) Exames de substâncias tóxicas: incluindo a categoria única "Alcoolemia, Substância Tóxica ou Entorpecente"; c) Exame de violência sexual, incluindo as categorias "Ato Libidinoso", "Conjunção Carnal", d) Exame de lesão corporal: incluindo as categorias "Integridade Física" e "Lesão Corporal". No caso da perícia criminal, os dados foram agregados da seguinte maneira: a) Exame de objetos: incluindo as categorias "Avaliação Indireta", Descrição de objetos" e "Instrumentos perfurantes, cortantes"; b) Exame de armas e substâncias químicas: incluindo as categorias "Armas de fogo" e "Química, Biologia e Alimentos"; c) Exames de homicídios, incluindo as categorias "Homicídio" e "Encontro de Cadáver"; d) Exames relacionados a ocorrências de tráfego, incluindo as categorias "Ocorrência de tráfego" e "Exame em veículos (geral)"; e) Exames diversos em locais, incluindo as categorias "Exame em veículo (chassi)", "Arrombamento", "Crime contra o patrimônio", "Exame em local (constatação)", "Incêndio", "Meio Ambiente", "morte".

Uma questão relevante é que foram apenas analisadas as estatísticas referentes à polícia técnica (órgãos vinculados ao DGPTC). Não foram, portanto, incluídos nas análises os dados referentes às equipes de perícia vinculadas às Divisões de Homicídios, as quais atendem as regiões da capital, Baixada Fluminense e grande Niterói (municípios de Niterói e São Gonçalo).

Para as análises estatísticas foi utilizado o software PAST (Hammer et. al., 2001), disponibilizado no site: http://palaeo-electronica.org/2001_1/past/issue1_01.htm. As análises de medidas de tendência central (média, desvio padrão e coeficiente de variação) foram obtidas para os dados de demanda de exames periciais. Foram realizadas correlações de Pearson entre as variáveis temporais (demandas de exames periciais e indicadores de criminalidade), adotando-se o nível de significância de $95 \%$. Para cada posto de perícia foi obtido o somatório (de todo o período analisado) da demanda de exames, total de registros de ocorrência, proporção entre demanda de exames e número de registros de ocorrência, área total atendida e população abrangida. Foram realizadas correlações de Pearson entre estas variáveis geradas. Foi construída uma matriz com os dados de indicadores de criminalidade e de demanda por tipo de exame para a perícia médico-legal, o qual foi submetida à análise de agrupamento hierárquico (cluster analysis), com média de pares de grupos não ponderados (Unweighted pair-group average UPGMA) e utilizando-se da distância Euclidiana.

Os gráficos foram produzidos no Programa Microsoft Excel (2013).

\section{Resultados}

\subsection{Caracterização espacial das Unidades de Perícia do Estado do Rio de Janeiro}

As unidades de Polícia Técnico-Científica do estado do Rio de Janeiro estão subordinadas ao Departamento Geral de Polícia Técnico-Científica e abrangem unidades administrativas denominadas de Postos Regionais de Polícia TécnicoCientíficas (PRPTCs) distribuídas pelo interior do estado e que agregam em sua estrutura as funções de perícia criminal, perícia médico legal e papiloscopia. Já na cidade do Rio de Janeiro, as unidades de perícia estão vinculadas a um dos quatro institutos, a saber: Instituto de Criminalística Carlos Éboli (ICCE), Instituto de Medicina Legal Afrânio Peixoto (IMLAP), Instituto de Pesquisa e Perícia em Genética Forense (IPPGF) e Instituto de Identificação Afrânio Peixoto (IIFP). Os institutos realizam não só os exames periciais da cidade do Rio de Janeiro, mas também grande parte dos exames especializados provenientes de todo o estado. Adicionalmente, a cidade do Rio de Janeiro é atendida pelo PRPTC de Campo Grande. 
Os postos de polícia técnica do estado do Rio de Janeiro apresentam grande heterogeneidade relacionada à área de abrangência territorial e à população total atendida. A tabela 1 mostras as respectivas áreas de atendimento e o tamanho populacional correspondente para cada unidade administrativa de perícia, incluindo os Postos Regionais de Polícia TécnicoCientífica (no interior do estado, além de Niterói e São Gonçalo) e a cidade do Rio de Janeiro (institutos e PRPTC de Campo Grande).

Tabela 1: Unidades de Polícia Técnico-Científica e respectivas áreas, municípios atendidos e população abrangida, no período estudado.

\begin{tabular}{|c|c|c|c|}
\hline Postos de Perícia (PRPTC) & $\begin{array}{l}\text { População } \\
\text { (2010) }\end{array}$ & $\begin{array}{c}\text { Área } \\
\text { abrangida } \\
\left(\mathrm{km}^{2}\right)(2015)\end{array}$ & Municípios atendidos \\
\hline Sede / Campo Grande & 6.507 .723 & 1.758 & Rio de Janeiro, Itaguaí, Seropédica \\
\hline Angra dos Reis & 260.925 & 2.944 & Angra dos Reis, Mangaratiba, Parati, Rio Claro \\
\hline Araruama & 263.142 & 2.386 & Araruama, Rio Bonito, Saquarema, Silva Jardim \\
\hline Barra do Piraí & 291.765 & 3.738 & $\begin{array}{c}\text { Barra do Piraí, Eng }{ }^{\circ} \text { Paulo de Frontin, Mendes, Miguel Pereira, Paty do Alferes, } \\
\text { Rio das Flores, Valença, Vassouras }\end{array}$ \\
\hline Cabo Frio & 352.228 & 1.026 & $\begin{array}{l}\text { Armação dos Búzios, Arraial do Cabo, Cabo Frio, Iguaba Grande, São Pedro da } \\
\text { Aldeia }\end{array}$ \\
\hline Campos dos Goytacazes & 575.375 & 6.636 & Campos dos Goytacazes, São Fidélis, São F. de Itabapoana, São J.da Barra \\
\hline Duque de Caxias & 1.427 .382 & 697 & Duque de Caxias, Magé (parte), São J. de Meriti \\
\hline Itaperuna & 214.722 & 3.902 & $\begin{array}{c}\text { Bom Jesus de Itabapoana, Cardoso Moreira, Italva, Itaperuna, Laje do Muriaé, } \\
\text { Natividade, Porciúncula, São José de Ubá, Varre-e-Sai }\end{array}$ \\
\hline Macaé & 402.563 & 3.275 & $\begin{array}{c}\text { Carapebus, Casimiro de Abreu, Conceição de Macabú, Macaé, Quissamã, Rio das } \\
\text { Ostras }\end{array}$ \\
\hline Niterói & 615.023 & 496 & Maricá, Niterói \\
\hline $\begin{array}{l}\text { N. Friburgo (Serviço de Pericia } \\
\text { Criminal) }\end{array}$ & 284.484 & 4.041 & $\begin{array}{c}\text { Bom Jardim, Cantagalo, Cordeiro, Duas Barras, Macuco, Nova Friburgo, Santa } \\
\text { Maria Madalena, Trajano de Moraes }\end{array}$ \\
\hline $\begin{array}{l}\text { N. Friburgo (Serviço de } \\
\text { Medicina Legal) }\end{array}$ & 338.757 & 4.995 & $\begin{array}{l}\text { Bom Jardim, Cachoeira de Macacú, Cantagalo, Cordeiro, Duas Barras, Macuco, } \\
\text { Nova Friburgo, Santa Maria Madalena, Trajano de Moraes }\end{array}$ \\
\hline Nova Iguaçu & 1.871 .968 & 993 & Belfort Roxo, Japeri, Mesquita, Nilópolis, Nova Iguaçú, Paracambi, Queimados \\
\hline Petrópolis & 295.917 & 795,8 & Petrópolis \\
\hline Resende & 177.937 & 1.677 & Itatiaia, Porto Real, Quatis, Resende \\
\hline Santo A. de Pádua & 124.266 & 2.393 & $\begin{array}{l}\text { Aperibé, Cambuci, Itaocara, Miracema, Santo Antônio de Pádua, São Sebastião do } \\
\text { Alto }\end{array}$ \\
\hline São Gonçalo & 1.302 .741 & 1.777 & Cachoeira de Macacú, Itaboraí, São Gonçalo, Tanguá \\
\hline Teresópolis & 381.475 & 2.266 & $\begin{array}{c}\text { Carmo, Guapimirim, Magé (parte), São José do V.R Preto, Sumidouro, } \\
\text { Teresópolis }\end{array}$ \\
\hline Três Rios & 155.644 & 1.666 & Areal, Comendador Levy Gasparian, Paraíba do Sul, Sapucaia, Três Rios \\
\hline Volta Redonda & 484.649 & 1.312 & Barra Mansa, Pinheral, Piraí, Volta Redonda \\
\hline
\end{tabular}

* Os Serviços de Medicinal Legal e de Perícia Criminal do Posto de Polícia Técnica de Nova Friburgo apresentam área de atuação diferenciada, por isso foram mostrados em separado. Em todos os outros há coincidência da abrangência.

Fonte: IBGE, Data RIO e Instituto de Segurança Pública (ISP/RJ)

Importante ressaltar que a divisão territorial dos Postos de Polícia Técnica não segue a divisão territorial das demais unidades de polícia, as quais foram delineadas ainda em 1999 através da Resolução SSP n 263 que definiu as Áreas Integradas de Segurança Pública (AISP). O objetivo das AISP foi a integração espacial das ações e dados referentes à criminalidade no âmbito das polícias civil e militar. As áreas de abrangências das AISP foram estabelecidas com base na área de atuação de Batalhões de Polícia Militar e nas circunscrições das Delegacias de Polícia Distritais. A divisão atual contempla um total de 39 AISPS. Posteriormente, o Decreto estadual $n^{\circ} 41.930$ de 26 de novembro de 2009 estabeleceu as Regiões Integradas de Segurança Pública (RISP) que articulam em um nível espacial mais amplo as AISPs dentro de regiões do estado, com 
correspondentes na estrutura organizacional da Polícia Militar através dos Comandos de Policiamento de Área e de parte da Polícia Civil através dos Departamentos de Polícia de Área. Neste último caso, não está incluída a Polícia Técnica. Dessa forma, para que fosse feita uma correspondência entre os índices de criminalidade registrados pelo Instituto de Segurança Pública (ISP) - os quais estão agregados em AISPs e RISPs - foi feita uma análise caso a caso. A Tabela 2 mostra a equivalência das unidades de perícia do estado em relação às ISPs e AISPs.

Tabela 2: Correspondência entre áreas de atendimento das unidades de polícia técnica (bairros e municípios) com a divisão territorial por AISPs (Áreas integradas de Segurança Pública) e RISPs (Regiões Integradas de Segurança Pública) do estado do Rio de Janeiro, no período abrangido pelo estudo.

\begin{tabular}{|c|c|c|}
\hline Postos de Perícia (PRPTC) & AISP & RISP \\
\hline Sede - Campo Grande & $\begin{array}{l}2,3,4,5,6,9,14,16,17,18,19,22 \\
23,24 \text { (parte), } 27,31,40,41\end{array}$ & 1,2 e 3 (parte) \\
\hline Angra dos Reis & 33 & 5 \\
\hline Araruama & 25 (parte) e 35 (parte) & 4 \\
\hline Barra do Piraí & 10 (parte) & 5 \\
\hline Cabo Frio & 25 (parte) & 4 \\
\hline Campos dos Goytacazes & 8 & 6 \\
\hline Duque de Caxias & $15,21,34$ (parte) & 3 \\
\hline Itaperuna & 29 & 6 \\
\hline Macaé & 32 & 6 \\
\hline Niterói & 12 & 4 \\
\hline $\begin{array}{l}\text { Nova Friburgo (Serviço de } \\
\text { Perícia Criminal) }\end{array}$ & 11 & 7 \\
\hline $\begin{array}{l}\text { Nova Friburgo (Serviço } \\
\text { médico-legal) }\end{array}$ & 11,35 (parte) & 7,4 \\
\hline Nova Iguaçu & 20,24 (parte), 39 & 3 \\
\hline Petrópolis & 26 & 7 \\
\hline Resende & 37 & 5 \\
\hline Santo Antônio de Pádua & 36 & 6 \\
\hline São Gonçalo & 7,35 (parte) & 4 \\
\hline Teresópolis & 30,34 (parte) & 3,7 \\
\hline Três Rios & 38 & 7 \\
\hline Volta Redonda & 28,10 (parte) & 5 \\
\hline
\end{tabular}

\subsection{Demanda de Exames periciais dos Postos Regionais de Polícia Técnico-Científica (PRPTC) e Sede}

A série temporal para o período de julho de 2013 a julho de 2016 revelou uma demanda por exames periciais bastante distinta entre os postos, com médias muito superiores na cidade do Rio de Janeiro em relação ao interior do estado. Já os postos de perícia da Baixada Fluminense (Duque de Caxias e Nova Iguaçu) e da região de Niterói e São Gonçalo apresentaram demandas intermediárias entre a sede e o interior (Tabela 3). 
Tabela 3: Demanda de exames periciais (perícia criminal e médico legal) para as unidades de polícia técnica e o total de registros de ocorrência consolidadas na região correspondente (média mensal e coeficiente de variação), para o período de julho de 2013 a julho de 2016.

\begin{tabular}{|c|c|c|c|c|c|c|}
\hline \multirow[b]{2}{*}{ PRPTC } & \multicolumn{2}{|c|}{$\begin{array}{l}\text { Demanda perícia } \\
\text { criminal }\end{array}$} & \multicolumn{2}{|c|}{$\begin{array}{l}\text { Demanda perícia } \\
\text { médico-legal }\end{array}$} & \multicolumn{2}{|c|}{$\begin{array}{c}\text { Demanda registros de } \\
\text { ocorrência }\end{array}$} \\
\hline & $\begin{array}{l}\text { Média } \\
\text { mensal }\end{array}$ & CV $(\%)$ & $\begin{array}{l}\text { Média } \\
\text { mensal }\end{array}$ & $\mathrm{CV}(\%)$ & $\begin{array}{l}\text { Média } \\
\text { mensal }\end{array}$ & CV (\%) \\
\hline Sede - Campo Grande & 4.570 & 13,7 & 6.019 & 6,8 & 33.058 & 5,8 \\
\hline Angra dos Reis & 182 & 30,6 & 226 & 22,9 & 895 & 10,1 \\
\hline Araruama & 186 & 22,1 & 204 & 12,0 & 960 & 8,1 \\
\hline Barra do Piraí & 213 & 22,9 & 248 & 12,0 & 738 & 6,9 \\
\hline Cabo Frio & 341 & 15,3 & 418 & 12,8 & 1.558 & 11,1 \\
\hline Campos Goytacazes & 424 & 29,2 & 393 & 35,5 & 1.637 & 7,4 \\
\hline Duque de Caxias & 397 & 30,1 & 1.168 & 13,1 & 5.561 & 7,2 \\
\hline Itaperuna & 252 & 16,6 & 201 & 15,7 & 682 & 5,2 \\
\hline Macaé & 275 & 35,3 & 338 & 11,8 & 1.671 & 7,6 \\
\hline Niterói & 487 & 22,2 & 625 & 21,2 & 3.055 & 5,5 \\
\hline Nova Friburgo Criminal & 283 & 34,0 & - & - & 929 & 9,3 \\
\hline Nova Friburgo IML & - & - & 308 & 27,0 & 1.091 & 8,3 \\
\hline Nova Iguaçu & 600 & 16,1 & 1.439 & 10,4 & 6.581 & 5,1 \\
\hline Petrópolis & 156 & 29,1 & 243 & 15,0 & 746 & 9,4 \\
\hline Resende & 312 & 21,2 & 213 & 11,1 & 764 & 11,5 \\
\hline Santo A. de Pádua & 179 & 20,5 & 138 & 16,1 & 422 & 11,6 \\
\hline São Gonçalo & 666 & 23,1 & 811 & 23,5 & 4.727 & 8,1 \\
\hline Teresópolis & 203 & 17,5 & 276 & 42,7 & 1.118 & 8,4 \\
\hline Três Rios & 179 & 21,0 & 161 & 20,3 & 551 & 10,7 \\
\hline Volta Redonda & 251 & 19,5 & 322 & 17,2 & 1.328 & 6,4 \\
\hline
\end{tabular}

Fonte: Departamento Geral de Polícia Técnico-Científica (DGPTC/SEPOL/RJ)

Houve discrepância em relação à variação de solicitações de perícias em alguns postos, sendo que para os Serviços de Perícia Criminal, os coeficientes de variação oscilaram de 13,7\% para a Sede (inclui Sede e PRPTC de Campo Grande) a 35,3\% para o PRPTC de Macaé. Embora o Serviço Médico-Legal tenha apresentado maior amplitude do coeficiente de variação entre postos: 6,8\% para a Sede a 42,7\% para o PRPTC de Teresópolis; as variações foram em geral menores do que para a perícia criminal. As demandas de registros de ocorrência obtidas pelo somatório dos ROs nas delegacias que compõem a área dos postos, foram ainda mais baixas, demonstrando uma maior constância temporal dos índices de criminalidade do que das demandas de exames periciais, para o período estudado. (Tabela 3).

Considerando-se a agregação dos dados da perícia em quatro grandes regiões: cidade do Rio de Janeiro, Baixada Fluminense, Interior do Estado e Niterói (Niterói e São Gonçalo) ${ }^{1}$, observou-se um grande desbalanceamento no número de ocorrências registradas pelas Delegacias que atendem nas respectivas áreas das unidades de polícia técnica. Quase 50\% dos

\footnotetext{
${ }^{1}$ As regiões abrangidas pela perícia não têm correspondência completa com as regiões administrativas estabelecidas para o estado do Rio de Janeiro, embora haja coincidência em grande parte dos municípios que compõe cada uma delas, conforme discutido anteriormente. Assim, os dados deste agregado não devem ser comparados com outros indicadores sócio-econômicos do estado.
} 
registros policiais ocorreram na cidade do Rio de Janeiro. Baixada e Interior apresentaram 18\% e 21\% respectivamente do total de registros de ocorrência, enquanto Niterói apresentou somente 12\% (Figura 1)

Figura 1: Porcentagem de ocorrências registradas nas delegacias atendidas pelas unidades de polícia técnica, por região do estado, para o período de julho de 2013 a julho de 2016.

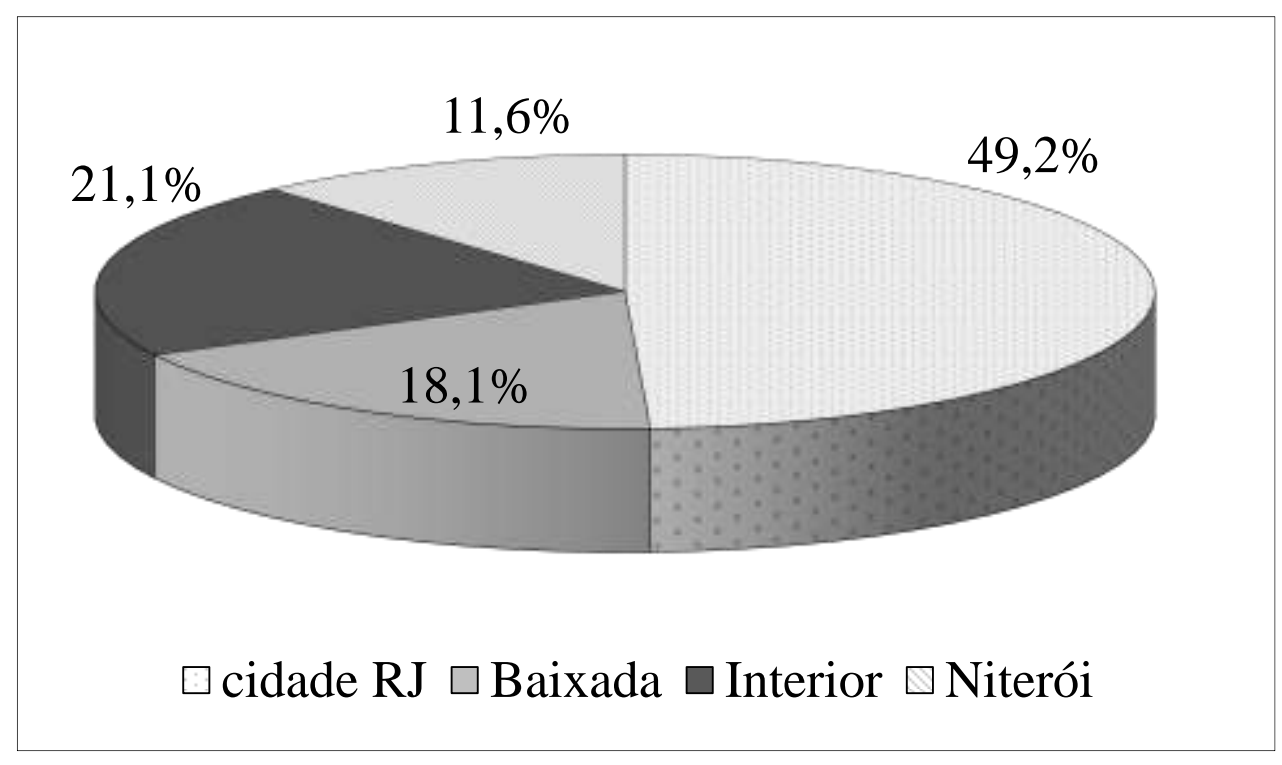

Fonte: Departamento Geral de Polícia Técnico-Científica (DGPTC/SEPOL/RJ).

Em relação à área de abrangência territorial das unidades de perícia, as discrepâncias são ainda maiores: 87\% do estado é atendido pelos PRPTCs do interior, enquanto as unidades da Baixada, Niterói e cidade do Rio de Janeiro, correspondem a 5\%, ou menos da área geográfica do estado (Figura 2).

Figura 2: Porcentagem da área atendida pelas unidades de polícia técnica, por região do estado, para o período de julho de 2013 a julho de 2016.

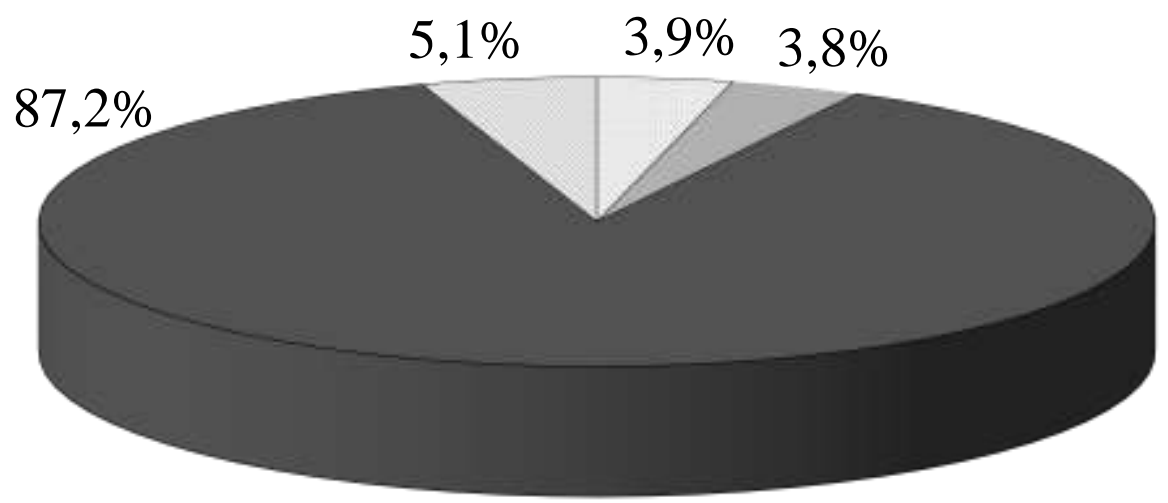

\section{$\square$ cidade RJ $\square$ Baixada $\square$ Interior $\square$ Niterói}

Fonte: Departamento Geral de Polícia Técnico-Científica (DGPTC/SEPOL/RJ). 
Quanto à população atendida, as diferenças regionais são menores, mas ainda assim bastante pronunciadas e apresentam certa correspondência, como esperado, com o número de registros de ocorrência (Figura 3).

Figura 3: Porcentagem de população do estado atendida pelas unidades de polícia técnica, por região do estado, para o período de julho de 2013 a julho de 2016.

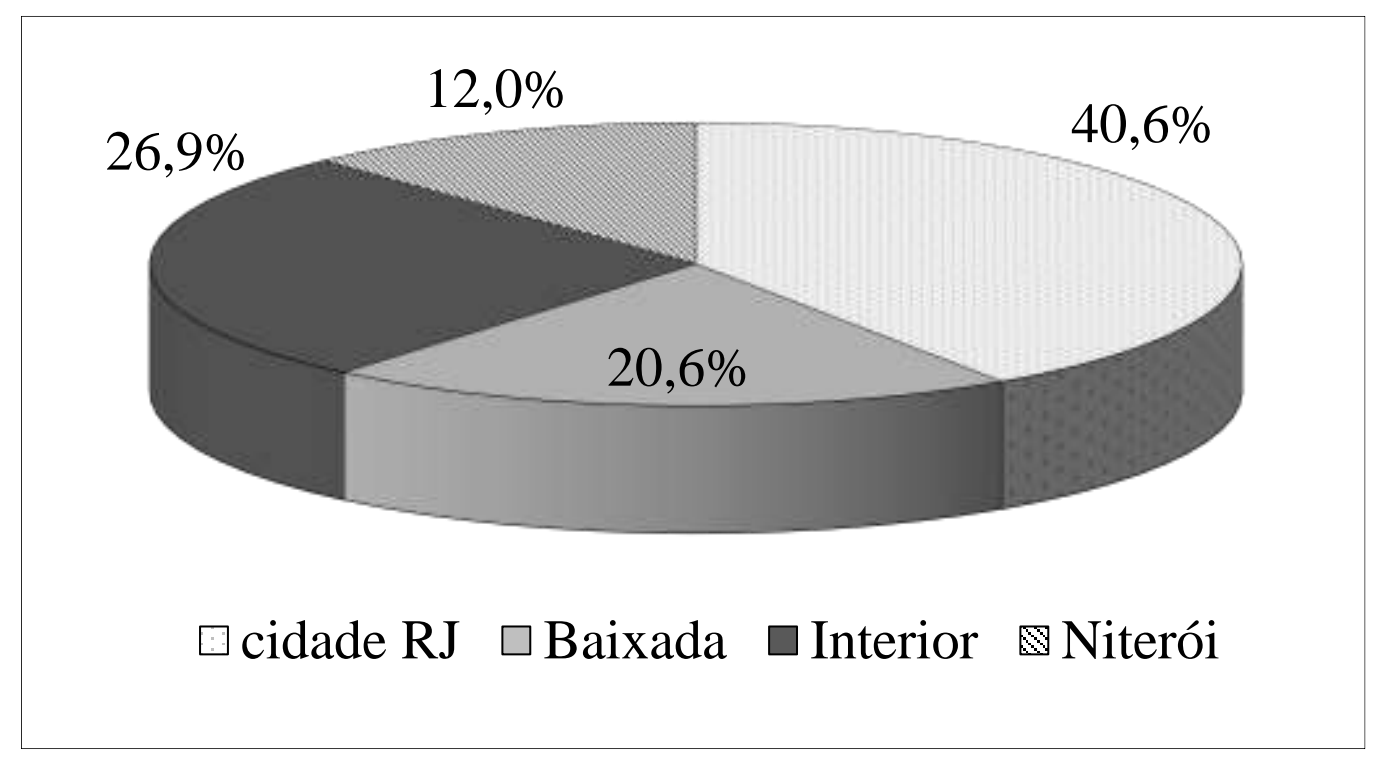

Fonte: Departamento Geral de Polícia Técnico-Científica (DGPTC/SEPOL/RJ)

A demanda de perícias criminais mostrou um padrão bastante divergente do obtido para o número de registros de ocorrência de cada região do estado. Na Baixada Fluminense, por exemplo, 18\% de todos os ROs ocorreram em delegacias dessa região, enquanto apenas $8 \%$ de todas as perícias foram realizadas nessa mesma região. O fato se inverte no interior do estado, onde mais perícias foram realizadas proporcionalmente ao número de registros de ocorrência. A perícia médico-legal, ao contrário, apresentou frequências de demandas de perícias mais próximas à distribuição de registros de ocorrência no estado, por região (Tabela 4).

Tabela 4: Porcentagem de demanda por perícia criminal e perícia médico-legal e quantitativo de peritos, por região do estado, para o período de julho de 2013 a julho de 2016.

\begin{tabular}{lcccc}
\hline & \multicolumn{2}{c}{ Serviço de Perícia Criminal } & \multicolumn{2}{c}{ Serviço de Perícia Médico-Legal } \\
\hline & Peritos & Demanda & Demanda & Peritos \\
& $(\%)$ & $(\%)$ & $(\%)$ & 43,8 \\
\hline Cidade RJ & 53,2 & 45,0 & 45,5 & 19,0 \\
Baixada & 8,0 & 9,8 & 9,4 & 26,8 \\
Interior & 31,1 & 33,8 & 35,4 & 10,4 \\
Niterói & 7,7 & 11,4 & 9,7 & \\
\hline
\end{tabular}

Fonte: Departamento Geral de Polícia Técnico-Científica (DGPTC/SEPOL/RJ).

O número de peritos alocados por região e por tipo de serviço (médico-legal e de perícia criminal) também apresentou diferenças marcantes, além de algumas incongruências. A demanda de perícia médico-legal foi proporcionalmente maior para a região da Baixada Fluminense do que para Niterói (quase o dobro). No entanto, a proporção de peritos alocados foi ligeiramente menor para a Baixada em relação a Niterói. Em relação ao serviço de perícia criminal a proporção de recursos humanos alocados foi proporcional à demanda por serviços (Tabela 4). A Sede abrigou, em todos os casos, quase a metade dos 
profissionais, sendo 49,2\% para a perícia criminal (214 peritos criminais) e 45,5\% (126 peritos legistas). Após a Sede, o interior apresentou o maior número de peritos alocados, sendo 125 peritos criminais $(31,1 \%)$ e 98 peritos legistas $(35,4 \%)$.

Adicionalmente foi feita uma análise detalhada para os tipos de ocorrência atendidos pelas unidades de polícia técnica, utilizando-se o ano de 2015. Para tanto, foram utilizadas as categorias definidas pela própria administração, as quais foram agregadas neste trabalho em cinco categorias para a perícia criminal e quatro categorias para a perícia médico-legal, conforme descrito na metodologia. Os dados da perícia criminal apontam para um padrão geral observado em todas as unidades de perícia, qual seja, a predominância absoluta de exames de objetos e de armas e substância, que corresponde a 50\% da demanda de perícia na Sede e de 70\% a $80 \%$ da demanda por perícias nas demais unidades de perícia (Tabela 5). As ocorrências de tráfego e locais diversos apresentam diferenças marcantes entre as unidades de perícia. No caso específico da sede, devido à realização de exames especializados não efetuados em grande parte das demais unidades de perícia, há claramente um desvio das frequências, principalmente na categoria denominada "locais diversos" que abrange os exames em locais de incêndio e meio ambiente.

Tabela 5: Frequência dos tipos de exames periciais (perícia criminal) efetuados pelas unidades de polícia técnica, para o ano de 2015.

\begin{tabular}{|c|c|c|c|c|c|}
\hline \multirow[b]{2}{*}{$\begin{array}{l}\text { Unidades de } \\
\text { perícia }\end{array}$} & \multicolumn{5}{|c|}{ Tipos de exames (\%) } \\
\hline & Objetos & Armas e subst. & Homicídios & $\begin{array}{c}\text { Ocorrências } \\
\text { de tráfego }\end{array}$ & $\begin{array}{c}\text { Locais } \\
\text { diversos }\end{array}$ \\
\hline Sede/C. Grande & 23,7 & 26,3 & 0,2 & 3,7 & 46,2 \\
\hline Angra dos Reis & 33,6 & 52,2 & $\mathbf{0 , 9}$ & 3,5 & 9,9 \\
\hline Araruama & 27,3 & 51,7 & 3,4 & 8,5 & 9,2 \\
\hline Barra do Piraí & 20,1 & 57,1 & 2,2 & $\mathbf{7 , 0}$ & 13,6 \\
\hline Cabo Frio & 28,7 & 57,2 & $\mathbf{3 , 0}$ & 5,4 & 5,7 \\
\hline Campos & 30,4 & 51,2 & 3,2 & 5,2 & 9,9 \\
\hline D. de Caxias & 29,1 & 48,3 & 0,2 & 9,9 & 12,6 \\
\hline Itaperuna & 38,9 & 39,0 & 0,4 & 6,7 & 15,0 \\
\hline Macaé & 45,1 & 35,8 & 5,3 & 5,8 & 8,0 \\
\hline Niterói & 40,7 & 36,6 & 0,2 & 13,6 & 9,0 \\
\hline Nova Friburgo & 29,3 & 42,9 & 2,0 & 8,4 & 17,5 \\
\hline Nova Iguaçu & 45,4 & 43,8 & 2,0 & 2,0 & 6,9 \\
\hline Petrópolis & 19,8 & 52,9 & 1,2 & 9,6 & 16,5 \\
\hline Resende & 30,2 & 37,3 & 1,3 & 6,1 & 25,2 \\
\hline S. A. de Pádua & $\mathbf{3 4 , 5}$ & 42,1 & 1,2 & 6,1 & 16,1 \\
\hline São Gonçalo & 33,2 & 41,3 & 1,0 & 14,5 & 10,0 \\
\hline Teresópolis & 25,6 & 46,9 & 2,0 & 11,3 & 14,3 \\
\hline Três Rios & 25,5 & $\mathbf{5 5 , 9}$ & 1,0 & 8,4 & 9,1 \\
\hline Volta Redonda & 28,3 & 49,6 & 3,1 & 5,7 & 13,3 \\
\hline
\end{tabular}

Fonte: Departamento Geral de Polícia Técnico-Científica (DGPTC/SEPOL/RJ). 
Os dados da perícia médico-legal mostram a predominância dos exames de lesão corporal, os quais abrangem de 77\% a quase $90 \%$ dos exames periciais. Os exames de necrópsia apresentam frequência variável, mas em alguns postos como Duque de Caxias e Nova Iguaçu (baixada Fluminense) essa frequência é superior aos demais, mesmo em relação à Sede. As necrópsias, incluem todas as mortes violentas, como homicídios, suicídios e acidentes em geral (Tabela 6). O que chama a atenção é a discrepância em relação aos exames de alcoolemia e de violência sexual que pode variar em uma escala de quase 10 vezes entre diferentes postos.

Tabela 6: Frequência dos tipos de exames periciais (perícia médico-legal) efetuados pelas unidades de polícia técnica, para o ano de 2015

\begin{tabular}{|l|cccc|}
\hline $\begin{array}{c}\text { Unidades de } \\
\text { perícia }\end{array}$ & necrópsia & Alcoolemia & $\begin{array}{c}\text { Violência } \\
\text { sexual }\end{array}$ & $\begin{array}{c}\text { Lesão } \\
\text { corporal }\end{array}$ \\
\hline Sede/C. Grande & $\mathbf{1 7 , 6}$ & $\mathbf{2 , 6}$ & $\mathbf{2 , 1}$ & $\mathbf{7 7 , 7}$ \\
\hline Angra dos Reis & $\mathbf{1 2 , 1}$ & $\mathbf{0 , 0}$ & $\mathbf{2 , 8}$ & $\mathbf{8 5 , 1}$ \\
\hline Araruama & $\mathbf{1 1 , 9}$ & $\mathbf{1 , 8}$ & $\mathbf{2 , 3}$ & $\mathbf{8 3 , 9}$ \\
\hline Barra do Piraí & $\mathbf{9 , 7}$ & $\mathbf{4 , 3}$ & $\mathbf{2 , 2}$ & $\mathbf{8 3 , 9}$ \\
\hline Cabo Frio & $\mathbf{1 2 , 5}$ & $\mathbf{1 , 9}$ & $\mathbf{0 , 9}$ & $\mathbf{8 4 , 7}$ \\
\hline Campos & $\mathbf{1 2 , 7}$ & $\mathbf{3 , 2}$ & $\mathbf{1 , 5}$ & $\mathbf{8 2 , 5}$ \\
\hline D. de Caxias & $\mathbf{2 3 , 6}$ & $\mathbf{1 , 6}$ & $\mathbf{4 , 1}$ & $\mathbf{7 0 , 7}$ \\
\hline Itaperuna & $\mathbf{1 0 , 7}$ & $\mathbf{1 , 5}$ & $\mathbf{0 , 0}$ & $\mathbf{8 7 , 7}$ \\
\hline Macaé & $\mathbf{1 2 , 0}$ & $\mathbf{1 , 4}$ & $\mathbf{3 , 9}$ & $\mathbf{8 2 , 8}$ \\
\hline Niterói & $\mathbf{1 0 , 7}$ & $\mathbf{3 , 4}$ & $\mathbf{2 , 1}$ & $\mathbf{8 3 , 8}$ \\
\hline Nova Friburgo & $\mathbf{1 0 , 8}$ & $\mathbf{3 , 3}$ & $\mathbf{2 , 7}$ & $\mathbf{8 3 , 1}$ \\
\hline Nova Iguaçu & $\mathbf{2 2 , 4}$ & $\mathbf{0 , 6}$ & $\mathbf{2 , 7}$ & $\mathbf{7 4 , 3}$ \\
\hline Petrópolis & $\mathbf{9 , 0}$ & $\mathbf{5 , 7}$ & $\mathbf{1 , 9}$ & $\mathbf{8 3 , 4}$ \\
\hline Resende & $\mathbf{7 , 4}$ & $\mathbf{1 , 5}$ & $\mathbf{2 , 2}$ & $\mathbf{8 8 , 9}$ \\
\hline S. A. de Pádua & $\mathbf{9 , 4}$ & $\mathbf{4 , 5}$ & $\mathbf{2 , 9}$ & $\mathbf{8 3 , 3}$ \\
\hline São Gonçalo & $\mathbf{1 6 , 6}$ & $\mathbf{1 , 0}$ & $\mathbf{2 , 4}$ & $\mathbf{7 9 , 9}$ \\
\hline Teresópolis & $\mathbf{8 , 0}$ & $\mathbf{3 , 7}$ & $\mathbf{1 , 6}$ & $\mathbf{8 6 , 7}$ \\
\hline Três Rios & $\mathbf{5 , 8}$ & $\mathbf{2 , 4}$ & $\mathbf{4 , 6}$ & $\mathbf{8 7 , 1}$ \\
\hline Volta Redonda & $\mathbf{8 , 7}$ & $\mathbf{0 , 7}$ & $\mathbf{1 , 2}$ & $\mathbf{8 9 , 5}$ \\
\hline \hline
\end{tabular}

Fonte: Departamento Geral de Polícia Técnico-Científica (DGPTC/SEPOL/RJ);

\subsection{Associação entre demanda pericial e indicadores de criminalidade}

Com base nos resultados sintetizados nas Tabelas 5 e 6 foram levantadas algumas hipóteses a serem analisadas através de testes de associação estatística. O objetivo foi verificar se a variação da demanda de exames periciais seria sensível a alguns dos índices de criminalidade. A expectativa inicial era de que os índices de lesões corporais e ocorrências de trânsito poderiam estar associados a um respectivo aumento na demanda dos exames médico-legais, pois estes indicadores implicam em aumento das vítimas que tipicamente são direcionadas para os exames de corpo de delito. Por outro lado, os índices de apreensão de armas e drogas deveriam repercutir no aumento da demanda de exames de perícia criminal, uma vez que estes objetos, uma 
vez apreendidos, necessariamente, pela legislação vigente, devem ser encaminhados para os órgãos periciais. Por outro lado, o aumento geral do número de ROs, implicaria em possível aumento das solicitações de exames periciais. Assim, foram testadas as seguintes hipóteses: a) as apreensões de armas e drogas consolidadas pelo número de registros de ocorrência do mesmo tipo poderiam ser um fator preditivo para a variação temporal da demanda de perícias nas unidades de perícia criminal, tendo em vista que armas e drogas representaram cerca de metade das solicitações da perícia criminal para quase todos os postos; b) os registros de ocorrência agregados nas categorias "lesões corporais" e "crimes de trânsito" poderiam ser um fator preditivo para a variação temporal da demanda de perícias nas unidades de perícia médico-legal. c) o número total de ocorrências consolidadas nas delegacias atendidas pelas unidades de polícia técnica estaria relacionado à demanda por exames periciais, tanto para a perícia criminal quanto para a perícia médico-legal.

Foi testada a associação estatística (correlação de Pearson) da série temporal de cada uma das 19 unidades de perícia criminal com os indicadores mensais de criminalidade (drogas apreendidas, armas apreendidas e total de registros de ocorrência). Em relação à perícia médico legal, foram realizados testes de associação entre as séries temporais de demanda de laudos de cada um dos 19 postos de perícia com os seguintes indicadores de criminalidade: lesões corporais, crimes de trânsito e total de registros de ocorrência. A fim de reduzir as distorções das diferentes proporções dos dados, os valores foram transformados pelo logaritmo de $\mathrm{X}+1$. Em todos os dezenove postos de perícia criminal e médico-legal houve uma baixa proporção de correlações estatisticamente significativas. Do total de 57 correlações, apenas $17(29,8 \%)$ resultaram em associação significativa e positiva para a perícia criminal e $16(28,0 \%)$ resultaram em associação significativa e positiva para a perícia médico-legal. A Tabela 7 mostra todas as correlações significativas, positivas ou negativas, com $\mathrm{p}<0,05$. 
Tabela 7: Correlações significativas das séries temporais da demanda de exames periciais das unidades de polícia técnica com os indicadores de criminalidade.

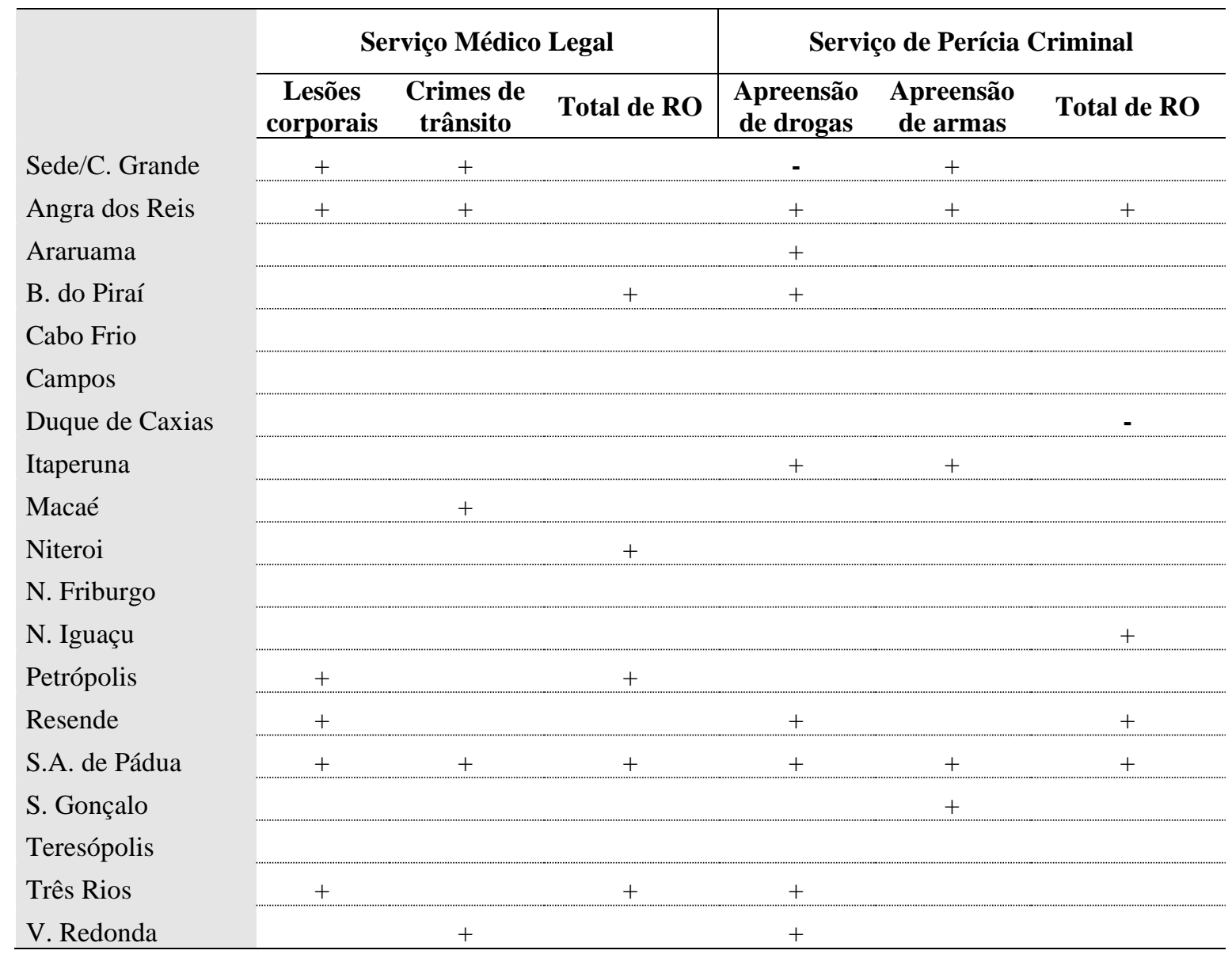

* - o símbolo “+” indica correlação positiva significativa e o símbolo “-” indica correlação positiva negativa, com nível de significância de 0,05 .

Fonte: Departamento Geral de Polícia Técnico-Científica (DGPTC/SEPOL/RJ)

Nenhum dos indicadores de criminalidade testado foi bom previsor para o número de exames periciais solicitados, embora a apreensão de drogas tenha apresentado associação com 9 dos 19 postos de perícia. Especificamente em relação ao total de ROs, apenas os seguintes postos de perícia criminal apresentaram correlação significativa: Angra dos Reis $(\mathrm{r}=-0,87$; $\mathrm{p} \leq 0,05)$, Nova Iguaçu $(\mathrm{r}=0,42 ; \mathrm{p} \leq 0,05)$, Resende $(\mathrm{r}=0,52 ; \mathrm{p} \leq 0,05)$ e Santo Antônio de Pádua $(\mathrm{r}=0,38 ; \mathrm{p} \leq 0,05)$. Os postos de perícia médico legal que apresentaram correlação estatisticamente significativa entre respectivas demandas dos postos e número de ROs foram: Barra do Piraí $(r=0,37 ; \mathrm{p} \leq 0,05)$, Niterói $(\mathrm{r}=0,43 ; \mathrm{p} \leq 0,05)$, Petrópolis $(\mathrm{r}=0,42 ; \mathrm{p} \leq 0,05)$, Santo Antônio de Pádua $(\mathrm{r}=0,57 ; \mathrm{p} \leq 0,05)$ e Três Rios $(\mathrm{r}=0,50 ; \mathrm{p} \leq 0,05)$. Portanto, não houve um padrão geral perceptível que permitisse uma generalização para todas as unidades periciais.

\subsection{Macro avaliação estrutural da demanda de exames periciais}

A análise macroestrutural do número total de perícias solicitadas em cada uma das unidades de perícia para o período de julho de 2013 a julho de 2016 mostrou que as unidades de perícia criminal e perícia médico legal apresentaram a mesma amplitude de variação entre os postos. Essa amplitude, por sua vez, acompanhou o número total de registros de ocorrências das delegacias de cada área abrangida (Figura 4). 
Figura 4: Número de registros de ocorrência (RO) e demanda de exames periciais para o Serviço Médico Legal (SML) e para o Serviço de Perícia Criminal (SPC). A comparação entre postos de perícia e registros de ocorrência foi realizado para o acumulado do período de julho de 2013 a julho de 2016.

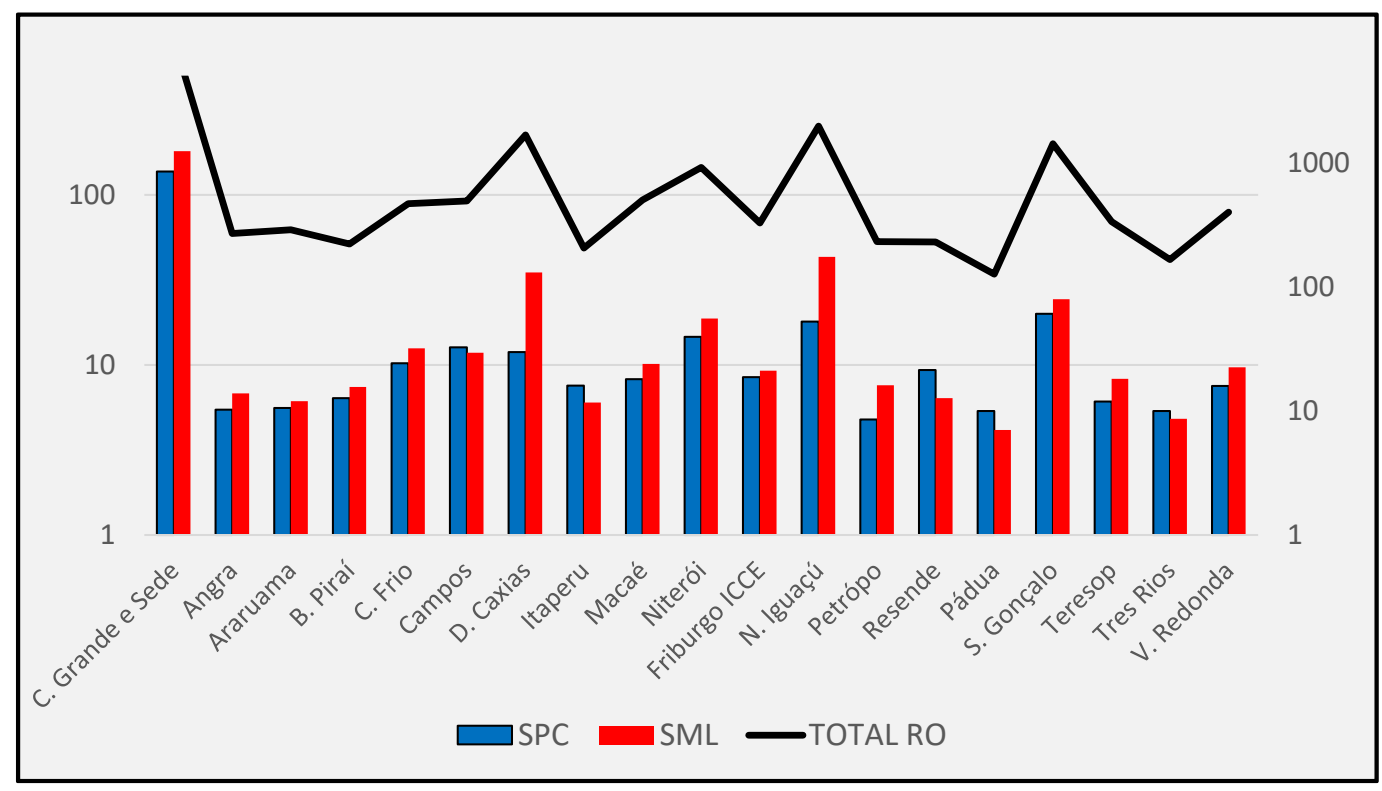

Fonte: Departamento Geral de Polícia Técnico-Científica (DGPTC/SEPOL/RJ).

Para testar a relação entre as variáveis de demanda de perícias e número total de registros de ocorrências foi realizado um teste de regressão linear, assumindo o nível de significância de 0,05\%. O número de registros de ocorrências (ROs) explicou significativamente a variação da demanda de perícias criminais $\left(\mathrm{r}^{2}=0,979 ; \mathrm{t}=28,39 ; \mathrm{p}<0,01\right)$ e da demanda de perícias médico-legais $\left(\mathrm{r}^{2}=0,998 ; \mathrm{t}=92,23 ; \mathrm{p}<0,01\right)$. Sendo assim, os índices de criminalidade, principalmente o número de registros de ocorrência pode ser utilizado para a previsão de diferenças entre postos de perícia. Contudo esse mesmo índice, bem como os demais analisados não são adequados para explicar as diferenças temporais ou variações da demanda de exames periciais ao longo do tempo.

A fim de aprofundar a análise, levantou-se a hipótese de que a quantidade de ROs registrados pelas delegacias atendidas pelas unidades de perícia teriam relação direta e constante com o número de solicitações de exames, ou seja, quanto maior o número de registros de ocorrência ocorreria um acréscimo, na mesma proporção do número de pedidos de exames para todos os postos. Para tanto foi calculada a proporção entre a demanda de exames periciais registrada em todo o período de estudo, para cada posto, e o número total de registros de ocorrência (dividindo-se a demanda de exames de cada posto pelo número total dos registros de ocorrência). Essa proporção foi considerada como a "taxa de conversão de ROs em pedidos de exames periciais". A Tabela 8 mostra a relação calculada para a perícia criminal e perícia médico-legal. A "taxa de conversão" foi baixa para todas as unidades de perícia. No caso do serviço médico legal, os exames periciais corresponderam de $17 \%$ a $33 \%$ do total de ROs. Enquanto no serviço de perícia criminal a taxa variou de 40 a 7,1\%. 
Tabela 8: “Taxa de conversão de registros de ocorrência em pedidos de exames periciais” para o Serviço de Perícia Criminal e Serviço Médico Legal, por unidade de perícia.

\begin{tabular}{|c|c|c|}
\hline Unidades de perícia & $\begin{array}{c}\text { Serviço de Perícia } \\
\text { Criminal }\end{array}$ & $\begin{array}{c}\text { Serviço de Medicina } \\
\text { Legal }\end{array}$ \\
\hline C. Grande e Sede & 13,8 & 18,2 \\
\hline Nova Iguaçu & 9,1 & 21,9 \\
\hline Duque de Caxias & 7,1 & 21,0 \\
\hline S. Gonçalo & 14,1 & 17,2 \\
\hline Niterói & 15,9 & 20,4 \\
\hline Macaé & 16,4 & 20,2 \\
\hline Campos & 25,9 & 24,0 \\
\hline Cabo Frio & 21,9 & 26,8 \\
\hline Volta Redonda & 18,9 & 24,3 \\
\hline Teresópolis & 18,1 & 24,7 \\
\hline Araruama & 19,4 & 32,1 \\
\hline Friburgo (ICCE) & 30,5 & 21,9 \\
\hline Angra dos Reis & 20,4 & 25,3 \\
\hline Petrópolis & 20,6 & 27,5 \\
\hline Resende & 40,8 & 31,9 \\
\hline Barra do Piraí & 28,8 & 33,6 \\
\hline Itaperuna & 37,0 & 29,4 \\
\hline Três Rios & 32,5 & 29,2 \\
\hline S. A. de Pádua & 42,5 & 32,8 \\
\hline
\end{tabular}

Fonte: Departamento Geral de Polícia Técnico-Científica (DGPTC/SEPOL/RJ).

Houve uma tendência ao aumento da proporção de perícias solicitadas conforme o número de ROs diminuía. Essa relação foi testada através do índice de correção de Pearson, transformando-se o número de ROs em logaritmo da base 10. Houve correlação negativa entre número de ROs e solicitações de exames periciais, tanto para a perícia criminal $(r=-0,736, p$ $<0,001)$ quanto para a perícia médico-legal $(\mathrm{r}=-0,772, \mathrm{p}<0,001)$. Isso significa que embora os registros de ocorrência influenciem positivamente no aumento da demanda de exames periciais, o grau dessa influência varia bastante entre as unidades de perícia. Em outras palavras, quanto maior o número de ocorrências das delegacias menor é o aumento da demanda de exames periciais solicitados.

Finalmente, as análises anteriores evidenciaram diferenças marcantes entre as unidades de perícia e entre a perícia criminal e perícia médico-legal, no que concerne à variação odo tipo de ocorrência, mudanças temporais e "taxas de conversão dos laudos". A fim de verificar graficamente essas diferenças, foi realizada uma Análise de Agrupamento Hierárquico (Unweighted pair-group average UPGMA), usando-se a distância Euclidiana. Para tanto foram utilizados os dados por tipo e quantidade de ocorrências das unidades de perícia, para todo o período estudado. A análise foi feita separadamente para o serviço de perícia criminal e para o serviço de perícia médico legal. Os dados do serviço médico legal mostram que houve uma clara separação entre Sede e demais unidades de perícia, seguida pelo agrupamento das unidades de São Gonçalo, Nova Iguaçu e Duque de Caxias. Em relação ao interior percebe-se a separação em três grupos distintos (Figura 5). 
Research, Society and Development, v. 10, n. 9, e49410918327, 2021

(CC BY 4.0) | ISSN 2525-3409 | DOI: http://dx.doi.org/10.33448/rsd-v10i9.18327

Figura 5: Análise de agrupamento (UPGMA) para as unidades de perícia médico legal.

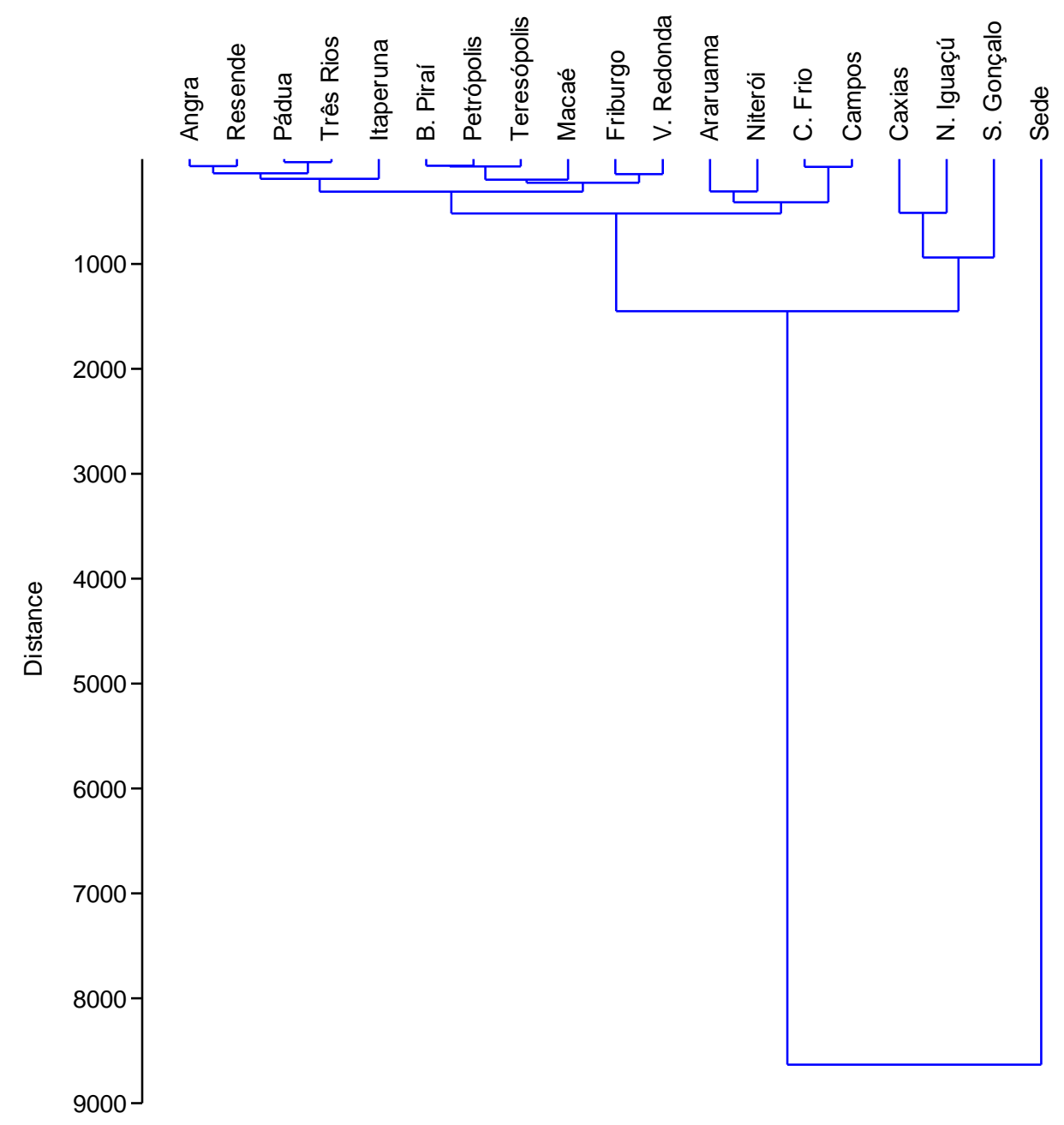

Fonte: Departamento Geral de Polícia Técnico-Científica (DGPTC/SEPOL/RJ).

Já os dados da perícia criminal mostram três grandes agregados: a Sede, um grupo formado pelos postos de São Gonçalo, Nova Iguaçu, Campos e Niterói e outro grupo com os demais postos de perícia (Figura 6). Isso demonstra que a dinâmica e as demandas das unidades de perícia devem ser consideradas de forma diferenciada para os serviços médico legal e de perícia criminal. 
Figura 6: Análise de agrupamento (UPGMA) para as unidades de perícia criminal.

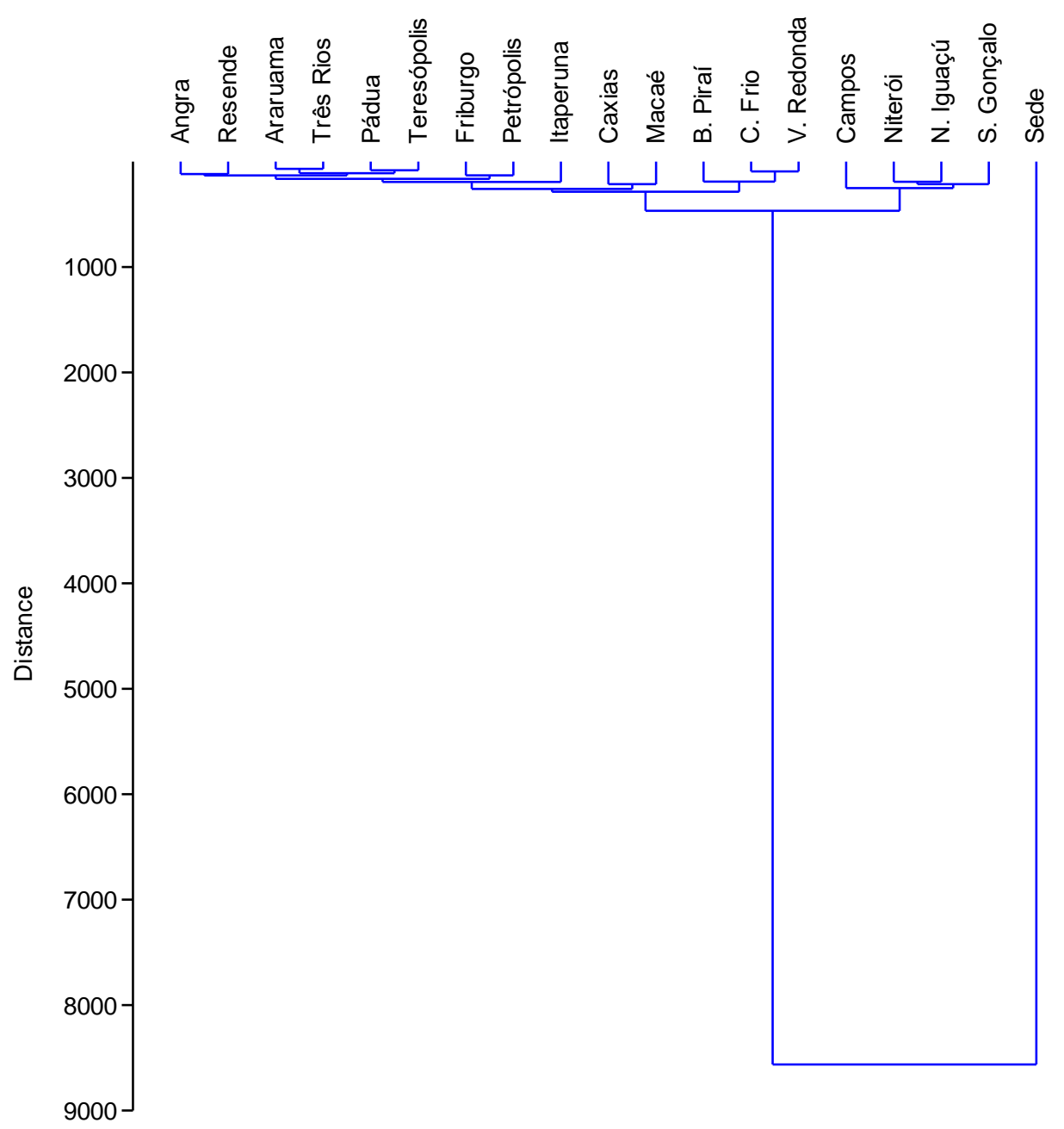

Fonte: Departamento Geral de Polícia Técnico-Científica (DGPTC/SEPOL/RJ)

\section{Discussão}

No Rio de Janeiro, desde 2005, alguns estudos vêm se debruçando sobre a questão da estruturação da polícia técnica, apontando as principais falhas relacionadas à gestão da informação, capacitação de recursos humanos, falta de insumos e ausência de procedimentos padronizados (Misse et al., 2009; Platero \& Vargas, 2017, Giovanelli \& Grazinoli, 2011, Misse et al., 2013, Medeiros, 2020). No entanto, no lapso de 15 anos não foram efetivadas mudanças significativas nos processos de trabalho da polícia técnica. Em última análise isso se deve à falta de clareza quanto às políticas de avaliação e fomento à perícia oficial. A perícia oficial ainda carece de indicadores claros para medição da eficiência do fluxo de trabalho e da produção pericial, bem como de critérios objetivos para alocação de recursos humanos e destinação de investimentos prioritários visando alavancar esse setor público de grande impacto social. Ressalta-se, no entanto, que este não é um problema, apenas, do Rio de Janeiro, mas de toda a perícia oficial no Brasil (SENASP, 2013). Estabelecer esses critérios objetivos faz-se urgente e necessário, a fim de nortear políticas de investimento, bem como potencializar a geração de dados qualitativos por parte da perícia. 
Uma constatação relevante sobre os dados gerados pela perícia oficial é sua completa ausência das estatísticas oficiais (uso primário) e como fonte de análises científicas. Para os dados de criminalidade, as principais fontes são os registros efetuados diretamente pelas delegacias de polícia ou batalhões de polícia militar, as declarações de óbito consolidadas no Sistema de Informação sobre Mortalidade (SIM), além da base de dados da SENASP e eventuais pesquisas quantitativas e pesquisas de vitimização (Borges \& Kirk, 2008). Em menor escala há fontes disponibilizadas por outros órgãos de segurança pública, como Polícia Rodoviária Federal (Andrade \& Antunes, 2019) ou pesquisas efetuadas sobre processos criminais no Ministério Público ou Judiciário. O presente trabalho buscou evidenciar o potencial do uso das informações geradas pela polícia técnica como ferramenta de a) planejamento estratégico, visando a alocação de recursos humanos e materiais, b) como base primária para a construção de indicadores de produtividade da perícia, c) como instrumento de avaliação da própria investigação policial. Esses fatores, na verdade, estão interligados e serão discutidos em conjunto.

Um primeiro fator que se destacou foi a série de gargalos institucionais que constituem problemas primários para a sistematização e análise de dados de forma consistente. A tabela 9 resume os principais problemas observados:

Tabela 9: Gargalos institucionais na polícia técnica do Rio de Janeiro que dificultam a sistematização e análise de dados gerados pela instituição.

\begin{tabular}{c} 
Gargalos institucionais observados \\
\hline Os dados são consolidados manualmente e ao Departamento Geral de Polícia Técnico-Científica, o \\
que pode introduzir falhas e ruídos, além de dificultar a organização e análise de dados, exigindo \\
retrabalho constante e exaustivas manipulações de planilhas dependendo do objetivo visado. \\
O foco da coleta de informação é sobre a análise de solicitações de laudos e laudos efetivamente \\
realizados (produtividade), para fins de controle administrativo da confecção de laudos \\
A perícia possui um sistema digital (SPTWeb) onde os laudos são confeccionados e \\
disponibilizados, mas esse sistema não é utilizado para geração de relatório estatístico. \\
A organização espacial da perícia não segue a mesma organização dos espacial das delegacias de \\
polícia civil e dos batalhões de polícia militar. Isso gera uma dificuldade adicional na correlação de \\
dados e na concatenação das políticas de integração institucional. \\
Não há padronização para a coleta de dados, que pode mudar de acordo com a administração e para \\
cada período, embora haja certa "constância" nas categorias consolidadas para cada unidade de \\
perícia
\end{tabular}

Fonte: Departamento Geral de Polícia Técnico-Científica (DGPTC/SEPOL/RJ).

Uma questão que chama a atenção é a subutilização de sistema informatizado já existente para a consolidação de relatórios estatísticos. Kahn (2014) ressalta que a "mera existência de dados e sistemas é condição necessária, mas não suficiente, para a melhoria da gestão" e ressalta a necessidade de informações de qualidade sobre as atividades dos órgãos periciais no Brasil, visando uma gestão adequada e eficiente.

Nesse sentido, os dados mesmo preliminares e circunscritos a um período de cerca de três anos, foram capazes de evidenciar alguns problemas relacionados à falta de planejamento orientado por informações consistentes. A análise da alocação de recursos humanos revelou inconsistência com a demanda de exames periciais. Esse é o caso da perícia médicolegal, cuja demanda de exames periciais foi quase duas vezes maior para a região da Baixada Fluminense do que para Niterói, enquanto o quantitativo de recursos humanos alocados foi ligeiramente menor para a Baixada Fluminense em relação a Niterói. Para a perícia criminal, no entanto, a alocação de recursos humanos foi compatível com a demanda pericial por região.

Mas além dessa constatação, se destaca o fato de haver um descompasso entre o volume de registros de ocorrência e a demanda por exames periciais, por região do estado. A hipótese mais óbvia seria que regiões diferentes apresentam 
composição criminal distinta e que isso se refletiria na demanda por exames periciais. No entanto, essa discrepância não ocorreu com a perícia médico-legal, mas sim com a perícia criminal que, em realidade, apresenta uma maior diversidade de atuação em crimes os mais diversos: homicídios, arrombamentos, acidentes de tráfego, exame de substâncias entorpecentes, exames de instrumento de crime, falsificações de documentos, descrição de objetos e outros. Trabalho realizado em 2012 sobre o fluxo da perícia em investigações de homicídios (Misse et. al, 2013) mostrou que as perícias realizadas no interior do estado tendem a gerar menos exames complementares do que aqueles realizados por peritos lotados na Divisão de Homicídios. Esses exames completares darão origem a novos laudos, o que aumentaria a demanda por exames periciais. Além dessa constatação, endógena ao serviço pericial, é possível que haja diferenças também em relação à proporção de pedidos de exames periciais feitos pelas delegacias da capital em relação às delegacias do interior. De uma maneira geral, a ênfase da investigação é pautada na prisão em flagrante, em detrimento de uma atuação mais técnica, embasada na prova pericial e procedimentos operacionais. (Costa \& Oliveira Júnior, 2016). Esse tipo de procedimento é ainda mais acentuado a depender da condição social da vítima (Platero \& Vargas, 2017). As diferenças regionais poderiam estar a refletir diferenças da atuação da investigação e não da dinâmica criminal. É possível que no interior do estado haja menor aderência da investigação policial à inserção de provas periciais. Um resultado que corrobora essa análise foi a constatação de que existe uma relação inversa entre o aumento de ROs e a proporção de pedidos que efetivamente irão se transformar em demanda de exames.

Assim, os dados consolidados da perícia, portanto, poderiam servir para mapear os pontos onde há uma menor “adesão" a pedidos de exames periciais, bem como embasar a criação de índices para avaliação de possíveis políticas públicas a serem implementadas.

No que concerne à criação de indicadores específicos para a polícia técnico-científica, a criação de uma base de dados de longo prazo, organizada sistematicamente e com parâmetros padronizados seria essencial. Alguns autores têm sugerido a criação de índices de avaliação de desempenho da perícia criminal que permitiriam avaliar a eficiência das unidades de perícia e servir de critério objetivo para alocação de recursos humanos e materiais, monitoramento de decisões administrativas e acompanhamento de metas (Belluco, 2012; Rodrigues \& Toledo, 2017). Em grande parte, a discussão sobre a eficiência e eficácia da perícia passa pela relação entre entrada de solicitações de laudo e a produção efetiva de laudos (SENASP, 2013), além de índice de laudos em atraso (Rodrigues \& Toledo, 2017). Embora seja reconhecida a necessidade de os índices incorporarem pesos relativos à complexidade dos exames, a quantidade e tipo de material examinado, a qualidade dos laudos e o tempo de deslocamento até o local, tais variáveis não são regularmente quantificadas nos institutos de perícia (Belluco, 2012). Assim, fatores organizacionais irão interferir diretamente na qualidade do laudo e no tempo dispendido pelo perito. No presente estudo, foi verificado que embora os postos do interior tivessem menos demanda por perícia, sua área de abrangência correspondia a mais de $80 \%$ do território do Rio de Janeiro. Esse fator deve ser mais crítico para a perícia criminal, dada a natureza de alguns tipos de exame que exigem o deslocamento do perito ao local do crime. No caso da perícia médico-legal, ao contrário, não há o deslocamento do perito. Para avaliar a implicação dessas variáveis na produtividade da perícia, é preciso que haja uma coleta e análise sistemática de dados.

A análise de dados relativos aos tipos de exames efetuados também é essencial para a criação de indicadores de eficiência da perícia, uma vez que o gasto de tempo e de insumos pode variar de acordo com o tipo de perícia. Observou-se que, embora a tanto a perícia criminal quanto médico legal tenham uma certa previsibilidade e constância em relação ao predomínio de certos exames, há variações importantes e de difícil explicação em relação a frequência relativa maior ou menor de acordo com a unidade de polícia técnica analisada. Esse é o caso dos acidentes de trânsito (perícia criminal) ou de exames de casos de estupros (perícia médico-legal). Em alguns postos essa frequência varia quase 10 vezes. É pouco provável que essa oscilação seja apenas explicada por diferenças nos padrões criminais. Nesses casos quais seriam os fatores? É possível que questões de ordem organizacional ou de gestão possam estar influenciando nessas taxas. 
Por fim, a análise de agrupamento confirmou que quaisquer gestores devem pensar a administração da perícia criminal e médico legal de forma integrada mas respeitando-se as peculiaridades a cada função. No Rio de Janeiro também ficou clara a existência de um modelo centralizado para a perícia criminal e médico legal, cujas sedes são responsáveis por $50 \%$ de todos os exames periciais no estado, incluindo a maioria dos exames especializados. Esse modelo pode não ser suficiente e adequado pois sobrecarrega algumas unidades. O ideal seria a criação de regionais que dispusessem de algum nível de especialização de atividades, a fim de distribuir melhor o atendimento à demanda de exames periciais do estado.

\section{Conclusão}

A análise de recorte temporal dos dados permitiu chegar a uma série de evidências importantes para a alocação de recursos humanos e materiais. No entanto, a análise sistemática dos dados para diagnósticos, deve levar em conta os seguintes pontos:

1) A organização espacial planejada para as unidades de perícia do estado não segue a normatização definida para as unidades de polícia judiciária e (delegacias) e de polícia militar. Estas últimas, inclusive estão inseridas em um planejamento integrado, inclusive com definição de metas específicas. O planejamento estratégico para a redução de índices de criminalidade, bem como a utilização dos dados da perícia como ferramenta adicional de diagnóstico da dinâmica criminal exige o reajuste da divisão espacial das unidades de perícia de acordo com o definido para o estado, em termos de áreas integradas de segurança pública;

2) A não integração das unidades de perícia à normativa existente de planejamento das ações de segurança pública, pode explicar parte dos resultados dissonantes observados em relação à alocação de recursos humanos e mesmo de demanda (discrepância entre registros de ocorrência e exames periciais) observados em determinadas regiões. Os dados produzidos pela perícia devem ser analisados em conjunto com os dados produzidos pelas delegacias, a fim de se construírem métricas para a avaliação de investimentos, alocação de recursos e reorganizações espaciais das próprias unidades periciais;

3) As unidades de perícia apresentam dinâmicas, em termos de demanda pericial, bastante diferenciadas, tanto em relação a aspectos espaciais (diferenças entre postos de perícia e entre regiões geográficas) quanto funcionais (diferença entre serviços de perícia criminal e serviços de perícia médico-legal). Em quaisquer análises essa estratificação deve ser considerada;

4) Os indicadores de criminalidade apresentam uma relação com a demanda de perícia, mas essa relação é distinta dependendo do nível observado. Isso significa que, por um lado, a dinâmica do trabalho pericial deve ser analisada em consonância com a dinâmica da investigação criminal, mas também há indícios de que haja fatores intrínsecos à perícia que precisam ser investigados e que atuariam com intensidade diferente entre as unidades de perícia.

5) A análise por tipo de exame revelou detalhes da dinâmica e diferenças importantes entre o serviço de perícia criminal e da perícia médico legal. A consolidação de categorias para a perícia criminal deve seguir uma lógica diferenciada daquela feita para a perícia médico-legal. Da mesma forma, a comparação com dados de criminalidade, como o número de homicídios, tem implicações diferentes para cada uma das funções de perícia (perícia criminal e perícia médico-legal).

6) Os dados de demanda de perícia precisam ser confrontados com outros indicadores, como distribuição de pessoal e até de recursos. O quantitativo de pessoal, inclusive pode ter implicações na quantidade de materiais processados pelas unidades de perícia e isso se refletir nos indicadores de demanda. Essa relação precisa ser melhor evidenciada em estudos posteriores.

Enfim, os dados apresentados indicam a necessidade de aprofundamento das informações geradas pela polícia técnica, a fim de permitir diagnósticos mais acurados sobre a distribuição de recursos humanos e materiais, bem como para servir de base à construção de indicadores do desempenho da perícia. Por outro lado, os órgãos periciais só realizam suas a atividades uma vez provocados por outras instituições, notadamente as polícias civis. Nesse sentido, seria interessante que as discussões 
de produtividade envolvessem a eficiência da delegacia na solicitação de exames, deslocando-se a discussão para o sistema de investigação policial como um todo, o qual deve funcionar de maneira integrada.

Em investigações futuras, seria relevante que se utilizasse o mesmo tipo de agregação de dados a fim de comparar a 'serie temporal, indicando tendências, modificações de padrões ou permanências. Além disso, agregar dados qualitativos às análises posteriores poderia potencializar a avaliação da eficiência do trabalho pericial. Nesse sentido, a indicação de infraestrutura dos postos, formação dos profissionais que compõe cada uma das unidades de polícia técnica e tempo de exercício nas atividades, poderia ser confrontada com a demanda de perícias, a fim de apontar fatores que possivelmente afetem a produção de exames.

\section{Referências}

Andrade, F. R. \& Antunes, J. L. F. (2019). Tendência do número de vítimas em acidentes de trânsito nas rodovias federais brasileiras antes e depois da Década de Ação pela Segurança no Trânsito. Cad. Saúde Pública, 35(8), e00250218.

Belluco, C. G. (2012). Indicadores de produtividade aplicados à criminalística da Polícia Federal. Dissertação de Mestrado - FGV, RJ, 89p.

Borges, D. \& Dirk, R. (2006). Compreendendo os Dados de Violência e Criminalidade. In: Miranda, A. P. M., Teixeira, P. A. S. \& Correa, R. M. (organizadores). Polícia e Comunidade: Temas e Desafios na Implantação de Conselhos Comunitários de Segurança. Coleção Instituto de Segurança Pública. Rio de Janeiro: Instituto de Segurança Pública.

Brasil (1941). Código de Processo Penal, “Capítulo II - Do exame do corpo de delito, e das perícias em geral. Decreto-Lei n 3.689 de 03 de outubro de 1941. Diário Oficial da União. Brasília.

Brasil. SENASP/MJ. (2013). Diagnóstico da Perícia Criminal no Brasil. Figueiredo, I. S. \& Pareschi, A. C. C. (Organização e revisão), Brasília: Ministério da Justiça, 124p.

Cano, I. \& Duarte, T. L. (2010). A mensuração da Impunidade no Sistema de Justiça Criminal do Rio de Janeiro. Coleção Segurança com Cidadania: Pesquisas Aplicadas em Segurança Pública, SENASP/MJ, 2, 9-44.

Costa; A. T. M. \& Oliveira Júnior, A. (2016). Novos padrões de investigação policial no Brasil. Revista Sociedade e Estado, 31(1).

Gil, A.C. (2017). Como elaborar projetos de pesquisa. Editora Atlas S.A.

Giovanelli, A. \& Garrido, R. G. (2011). A perícia criminal no Brasil como instância legitimadora de práticas policiais inquisitoriais. Revista LEVS, 7, 5-24.

Giovanelli, A. \& Souza, E. R. (2005). Informação da polícia técnica: paradoxo entre a relevância e o descaso. Revista Rio de Janeiro, 12 , 39-53.

Hammer, Ø., Harper, D. A. T. \& Ryan, P.D. (2001). PAST: Paleontological statistics software package for education and data analysis. Palaeontologia Electronica, 4(1), 1-9.

Kahn, T. (2014). Modelos de estruturação das atividades de polícia técnica e de perícia no Brasil. Rev. Bras. Segurança Pública São Paulo, 8(2), $198-217$.

Lima, R. K. \& Mouzinho, G. M. P. (2016). Produção e reprodução da tradição inquisitorial no Brasil: Entre delações e confissões premiadas. Revista Dilemas: Revista de Estudos de Conflito e Controle Social, 9(3), 505-529.

Lima, R. K. (2019). A polícia da cidade do Rio de Janeiro: seus dilemas e paradoxos. ed. Amazon.

Medeiros, F. (2016). “Matar o morto”: uma etnografia do Instituto Médico-Legal do Rio de Janeiro. Niterói: EdUFF, 221p.

Medeiros, F. (2020). Políticas de Perícia Criminal na Garantia dos Direitos Humanos. Relatório sobre a autonomia da Perícia Técnico-Científica no Brasil. Relatório Instituto Vladimir Herzog / Friedrich Ebert Stiftung, 32p.

Miranda, A. P. M., Oliveira, M. B. \& Paes, V. F. (2010). A Reinvenção da "Cartorialização": análise do trabalho policial em registros de ocorrência e inquéritos policiais em "Delegacias Legais" referentes a homicídios dolosos na cidade do Rio de Janeiro. Coleção Segurança com Cidadania: Pesquisas Aplicadas em Segurança Pública, SENASP/MJ, 4, 119-152.

Misse, M. (2010). O inquérito policial no Brasil - Uma pesquisa empirica. Rio de Janeiro, Booklink Publicações Ltda, 474p.

Misse, M., Giovanelli, A., Nepomuceno, D. \& Medawar, C. E. (2009). Avaliação da formação e da capacitação profissional dos peritos criminais no Brasil. Coleção Segurança com Cidadania: Pesquisas Aplicadas em Segurança Pública, SENASP/MJ, 1, 127-158.

Misse, M., Silva, K. A., Giovanelli, A., Siqueira, D. S. \& Nepomuceno, D. (2013). Fluxo do trabalho de perícia nos processos de homicídio doloso no Rio de Janeiro. Coleção Pensando a Segurança Púbica: Homicídios no Brasil: registro e fluxo de informações, SENASP/MJ, 1, $195-276$.

Pereira, A.S., Shitsuka, D. M., Parreira, F. J., \&Shitsuka, R. (2018). Metodologia da pesquisa científica. UFSM.

Platero, K. A. S. \& Vargas, J. D. (2017). Homicídio, suicídio, morte acidental... 'O que foi que aconteceu? Revista Dilemas: Revista de Estudos de Conflito e Controle Social, 10(3), 621-641. 
Research, Society and Development, v. 10, n. 9, e49410918327, 2021

(CC BY 4.0) | ISSN 2525-3409 | DOI: http://dx.doi.org/10.33448/rsd-v10i9.18327

Rangel, V. (2017). Os cinco sentidos da cocaína: saberes, hierarquias e controles sobre o uso e a manipulação do pó entre consumidores e peritos criminais. Tese de Doutorado. Programa de Pós-Graduação em Antropologia da Universidade Federal Fluminense, Niterói.

Ribeiro, L. \& Lima, F. M. (2020). Será que vai virar processo? Determinantes da elucidação dos homicídios dolosos em uma cidade brasileira. Opin. Publica, 26(1).

Rodrigues, C. V., \& Toledo, J. C. (2017). A medição de desempenho no serviço de Perícia Criminal: proposição e aplicação em uma unidade pericial. Rev. Bras. Segur. Pública, São Paulo, 11(1), 184-206.

Zaverucha, J. (2003). Polícia Civil de Pernambuco: o desafio da reforma. Editora Universitária UFPE. 